\title{
Perils, Pitfalls, Pristine Pearls and Prestige of Pinoy Nurse Educators in Oman: A Phenomenological Finding
}

\author{
Francis Carlos Lazarte, Maria Irma Bustamante, Ada Estephania Borjal Bonina, Nida Yu Baldo, and Imelda \\ De Leon Canlas
}

\begin{abstract}
The authors probed on the adaptation challenges experienced by Filipino nurse educators in a multicultural milieu in the Sultanate of Oman. The authors utilized Qualitative Interpretive-Existential Phenomenological design from saturated unstructured interview data with nine (9) female co-researchers. The transcribed data is rigorously analyzed through Van Manen's methodological interpretation. Based on the findings, Perils, Pitfalls, Pristine Pearls, and Prestige are the four major themes emerged from the common responses of Pinoy Nurse Educators, along with its derived sub-themes and numerous reduced related categories, respectively. Based from the overall findings, the authors discovered a resembled Filipino Bamboo-inspired See-Saw model which underpinned the adaptation challenges faced by these Filipino nurse educators to balance the Perils and Pitfalls with that of pearls and prestige when anchored with the proposed program on adaptation strategies and training of expatriates (PASTE) which included pre- \& post-departure advises and preparation (PDAP) strategies; and social, cultural, organizational, and personal expatriates (SCOPE) Training, set as a benchmark for global standard migration adaptation program.
\end{abstract}

Index Terms-Expatriate lived experience of nurse educators, Max van Manen's method, interpretative-existential phenomenological design, see-saw model, program on adaptation strategies, training of expatriates.

\section{INTRODUCTION}

\section{A. Background of the Study}

Any individual from all walks of life aim to achieve their goals and desires in life. In order to attain this, greater strength, courage, good will, and determination towards fulfillment of ambition is utmost needed. But fulfillment of sweet aspirations bound to take many risks including that of safety and security to work abroad in exchange of a greener pasture and better living for self, family, and loved ones.

Kierkegaard stated that "This constitutes proof of the Divine origin of the human since "what is great about the

Manuscript received February 24, 2015; revised July 6, 2015.

Francis Carlos Lazarte is with Amitie Review, Research, and Training Center, Inc. (ARRTCI), Davao City, Philippines (e-mail: drfrancis_lazarte@yahoo.com).

Maria Irma Bustamante is with the Graduate School Program, St. Paul University Manila, Philippines.

Ada Estephania Borjal Bonina is with the Oman Specialized Nursing Institute, Muscat, Sultanate of Oman.

Nida Yu Baldo is with the Rustaq Nursing Institute, Rustaq, Sultanate of Oman.

Imelda De Leon Canlas is with the Oman Nursing Institute, Muscat, Sultanate of Oman. human being, is that he can occupy himself' with the future and that this relation to the future is a struggle.

For Kierkegaard, truth is existentialised, that is, truth is about the bearing of the individual towards his or her own existence [1].

Uncertain of what to anticipate from another country's living situation due to lack of idea, knowledge, and awareness of the many aspects to consider as an overseas contract worker (OCW), a lot of adaptive strategies are made, but there are still lack of discourses on challenges and constraints. It is only until when the reality is faced which attests the truth that living a life abroad is strenuously difficult. The process of adjustment is never easy to endure by the struggles of working outside one's comfort zone in mingling with people of diverse racial and ethno-cultural backgrounds, influenced by religion, customs and traditions from their rooted origin. People from different cultures have different meanings and interpretation which oftentimes caused personal conflicts or professional misunderstanding. The exposure necessitates embracing the bizarre environment throughout the course of self-educating from host country, but often places the expatriates into cultural ambivalence and identity dilemma. Factors like gender sensitivity, level of position and experiences, as well as peculiarities of personality, comprehension and learning attitudes of Arab students from existing standard of educational system, and pressures from colleagues and administrators' expectation, superiors with misconstrued approach and style of management, at times abuse of vested power to the helpless subordinates, also complicates these challenges. On the other face of coin, few expatriates find themselves deterring the difficulty by drawing strength and faith in converting to host country's religion or engage into extramarital affairs for the instinctive means of survival.

The continuous struggle to live and adapt to the constrained budget due to salary and system delay, strongly affected financial needs for viability of expecting expatriate's families back home. Although rewarded of monetary gains from working like a day horse and night owl, expatriates lose every significant minute of their life, palpable in family's life event gatherings of loved ones.

Likewise, Overseas Filipino Workers (OFWs) find themselves emotionally troubled and immeasurably unprepared, usually burdened with the personal and family concerns while being miles away, confronting it while in stages of adjustments, wherein the faithful and fittest ones mostly survived and weaker ones get defeated, disused or deposed back to their country of origin, left empty-handed.

The authors' doubts in its endeavor to work in an international professional arena, especially in dealing with adjustments, and unsecured feeling of living and working in 
a strange country, dealing with daily travel safety and accommodation security issues, in getting along with varied individuals from different nationalities in a totally strange atmosphere of organization serves as a difficult training ground to realize that adapting to life abroad is not an easy process. Therefore, with the existent phenomenon being untold, it is a great must to go in-depth exploration, and is deemed necessary for adaptation strategies be developed and a proposed training program be meticulously exercised.

\section{B. Purpose of the Study}

To shed light on curiosity and have deeper search and understanding of the phenomenon, the authors of the study focused on exploring the experiences of Filipino Expatriate Nurse Educators, mainly the enriched data gathered from the co-researchers. They broke the silence of innocence, unveiled reality and uncovered the truth and fruit of their persevered life abroad on a broader and deeper note of holistic challenges and sacrifices from daily life and work situations, and extracted adaptation strategies from the challenges addressed by these individuals, as strategies of adapting, well-kept themselves for years.

\section{Statement of the Problem}

The study sought to answer the following research questions:

What are the adaptation challenges faced by the Filipino Expatriate Nurse Educators in a Multicultural Milieu in the Sultanate of Oman?

What adaptation training program can be developed to help address the challenges faced by the Filipino Expatriate Nurse Educators?

\section{Scope and Delimitation}

The scope of the study included Filipino Expatriate Nurse Educators, selected based on the criteria set by the authors. The co-researchers must be with at least 6 months of work experience as nurse educator, teaching any course subject or specialization at any academic level, with nursing curriculum as an educational program, possessed bachelor's, master's, and/or doctorate degree, and functioning as faculty or appointed with higher position. The study excluded Omani and other nationalities expatriate nurse educators, set as exclusion criteria, in order to protect the interests of their public citizen.

\section{E. Significance of the Study}

The research study explored on the life and work experiences and the adaptation challenges of Filipino expatriate nurse educators, with proposed Program on Adaptation Strategies and Training of Expatriate (PASTE). The study findings aimed to address many sectors of any government dealing with overseas recruitment and deployment, in general, and of great importance to the field of nursing profession, in specific.

The authors intended to benefit the following sectors of global nursing spectrum:

Clinical Nursing. Clinical Instructors working both as Clinical Nurse Practitioner and Educator, collaboratively dealing with other expatriates and locals in most hospital organization (government or private settings), different health care systems, may effectively develop professional camaraderie towards strong healthcare collaboration, updated clinical practice, culturally acceptable and adaptive performance based on the existing routine standards.

Curriculum in Nursing. The Geographical-Transcultural Nursing is suggested as new core or supplemental course subject addition to the Nursing Curriculum. It will generate knowledge to nursing students and preparedness of promising nurses who plan to work abroad in order to be more equipped with full understanding of the different countries employing Filipino Nurses, to emphasize understanding of the geographical location, customs, traditional background, norms and deviances in country's culture practices prior to job acceptance and engagement.

Nursing Educator. The expatriate nurse educators may imbibe cultural compassion and sensitivity to employees in any school organization, for both seasoned and new faculty, especially those on novice level, who recently work abroad with emphasis on employment recruitment, selection, and retention strategies suitable to an international setting, protect and serve equal justice to all employees, victim buffer and shock absorber of lateral violence and professional exploitation which mislead to forced termination, fast staff turnover and repatriation.

Research. The future researchers, from nursing field and other profession may be able to explore on the importance of extending further continuing studies related to this topic, and enhance the knowledge and skills to a culturallyequipped adaptation of nurses and educators and even nonprofessional employees.

Administration. The Coordinators, Deans of Nursing Schools, Directors of Nursing Affairs in hospitals may be able to find awareness and advocacy for the possible adaptation strategies and training program for newly hired staff and academician, unique from their regular induction program in their respective workplaces in order to strengthen multicultural workforce on its longer term.

Overseas Filipino Workers. To both professionals and non-professionals who live and work overseas, like nurse educators experiencing similar struggles and challenges in adapting to both workplace and home that they may be able to find aid, knowledge, strength and strategies from See-saw model, and Adaptation Training program. OFW cope with their daily challenges, overcome demands of their job, and meet expectations of their organization and standards of their profession.

Filipino Families of Overseas Workers In a hope that this study will bring awareness to all OFW family members, that they may value sacrifices of their breadwinners to keep safe, spend wisely the hard-earned fruits of labor, and value the struggles of those who chose to leave their comfort zone with empathy to the ones who risk their safety and security in hope of a better future of loved ones.

Philippine Embassies, DFA and POEA. To the Consulate Generals of Embassies all over the world, especially Gulf countries; as well as DFA and POEA linked authorities. This study may give greater emphasis on importance of adaptation measures for fellow Filipino expatriates working within their boundaries to seek awareness, follow-up on stability and assurance of the comfort, safety and satisfaction of expatriate condition, provide training and strategies to prevent avoidable casualties \& unreported incidents by revisiting standard protocols and assistance. 
Foreign Employers/Agencies Abroad. The employers dealing with expatriate workforce, may reflect on the research findings, taking into account the adaptation strategies and training programs to strengthen workforce stability of employees, and modification of the systems involving operations on "recruitment and retention".

\section{F. Operational Definitions}

Adaptation Challenges refers to the life and work challenges of Filipino expatriate nurse educators presently working in the Sultanate of Oman

Co-researchers refer to the respondents, mainly considered as the second \& third person of the study, are presently working in Oman for at least 6 months.

Expatriates refer to as individuals who are working abroad and away from their home country. It is defined as employees who are transferred out of their home base into some area of the firm's international operations [2].

Multicultural Milieu refers to the workplace with workers from different nationalities gathered in a different milieu. A diversified work environment pooled by employees hired all over countries, taken with them their varied cultures, customs, traditions, values, opinions, broad age-range and diversity of workforce including Filipino nurse educators.

Perils refer to the exposure to the risk of harm or loss, something that endangers or involves risk, expose to danger or chance of injury [3]. The authors described this as potential risk or impending ambivalence that may put or endanger Filipino expatriate nurse educators from withholding emotional stability and mental sanity.

Pinoy refers to etymologic word for Filipino race, also easily identified and known internationally with terms used such as Kabayan or Filibini in Arabic countries.

Pitfalls refer to an unapparent source of trouble or danger; a hazard, or concealed hole in the ground that serves as a trap [3]. The authors described this as hardship encounter, a downfall circumstances, placed into worst blowing situations that burdens or hinders the Filipino expatriate nurse educators from usual freedom or restrict to exercise rights in employment and practice.

Prestige are described by the authors as the high regard reputation earned by the Filipino expatriate nurse educators from working very hard to generate the respect, trust, and credibility with an everlasting aim to attain the pedestal of success, freedom, and legacy.

Pristine Pearls are tangible or intangible rewards earned from all hard works, and hard-earned money and sacrifices made by the expatriates in working abroad. Pristine means pure state or free from dirt, Pearls, are identified as the genuine gem or treasures.

Program of Adaptation Strategies and Training of Expatriates (PASTE) is the end result strategies of proposed program based on findings of the research. It may be considered as a baseline for advanced, customized induction of nurse educators, staff nurses, and other health care professionals aim to be settled in international employment setting.

See-Saw Model is a model that serves as a foundation which tries to figure out the equation between the baggage of challenges evidenced by many perils and pitfalls balancing with the pursuit to gain the pristine pearls and prestige from their decision to live and work abroad.

\section{Methodology}

\section{A. Research Design}

The authors conducted a qualitative study and utilized Phenomenological research design.

The worldview of Phenomenology is more unique and controversial. The world shapes the self and the self shapes the world. It is both a philosophy in which stated Phenomenological Research, view the person integrated with the environment. Phenomenologist, differ in their philosophical beliefs [4]. Phenomenology is the study of phenomena from a human perspective. Phenomenology seeks to develop an understanding of lived experience. The first hand report or description of one's experience of the phenomenon is central to understanding the phenomenon. The meaning one creates in the world is socially constructed and is rooted in the experiences of the person. Meaning occurs through ongoing social processes [5].

\section{B. Philosophy of Method}

Taking into consideration on the philosophical underpinnings of the study, adaptation challenges of Filipino expatriate nurse educators, the philosophical basis used is Interpretive-Existential Phenomenological method, which is consistent within the branch of qualitative phenomenological research. Van Manen urge qualitative researchers to keep in mind that literature, music, painting, and other art forms can provide a wealth of experiential information that can increase insights as the phenomenologists tries to interpret and grasp the essential meaning of the experience being studied [6]. The purpose of interpretation recognized the patterns or themes from an experience of the co-researchers of study (see Table I).

TABLE I: METHODOLOGICAL INTERPRETATION FOR EXISTENTIAL PHENOMENOLOGY (VAN MANEN 1990, 1997, 2008)

\begin{tabular}{|c|}
\hline Procedural Steps \\
\hline $\begin{array}{l}\text { 1) Turn to the nature of lived experience by orienting to the } \\
\text { phenomenon, formulating the phenomenological question, and } \\
\text { explicating assumptions and pre-understandings. } \\
\text { 2) Engage in existential investigation, which involves exploring the } \\
\text { phenomenon: generating data, using personal experience as a starting } \\
\text { point, tracing etymologic sources, searching idiomatic phrases, } \\
\text { obtaining experiential descriptions from participants, locating } \\
\text { experiential descriptions in the literature, and consulting } \\
\text { phenomenological literature, art and so forth. } \\
\text { 3) Engage in phenomenological reflection, which involves } \\
\text { conducting thematic analysis, uncovering thematic aspects in life- } \\
\text { world descriptions, isolating thematic statements, composing } \\
\text { linguistic transformations, and gleaning thematic descriptions from } \\
\text { artistic sources. } \\
\text { 4) Engage in phenomenological writing, which includes attending } \\
\text { to the speaking of language, varying the examples, writing, and } \\
\text { rewriting. }\end{array}$ \\
\hline
\end{tabular}

Philosophy is the ways of knowing, personal knowing requires that the individual - know the self. The degree to which an individual knows oneself is determined by his or her abilities to self-actualize. Movement towards knowledge of the self and self-actualization requires comfort with ambiguity and a commitment to patience in understanding [7]. Kierkegaard (1989) mentioned that "indeed, this is concern with the way in which an Individual exists is 
precisely the concern of philosophy itself as expressed by Socrates urging 'care for oneself" [1].

The methodological interpretation that is used to provide meaningful direction to this phenomenon is van Manen (2008) procedural steps [7], [8].

\section{Research Approach}

One of the main reasons for the increased popularity of phenomenology in nursing research is that it provides a research approach that is consistent with the art, philosophy and practice of nursing: "understanding unique individuals and their meanings and interactions with others and the environment" [9]. The approach of research is phenomenological in nature, the research explored on the existing life and work experiences of nurse educators abroad specifically in Oman. The authors probed the coresearchers' adaptation challenges as well as their continuous struggles and how are they coping to the battlefield and the adaptation strategies they utilized.

\section{Research Locale}

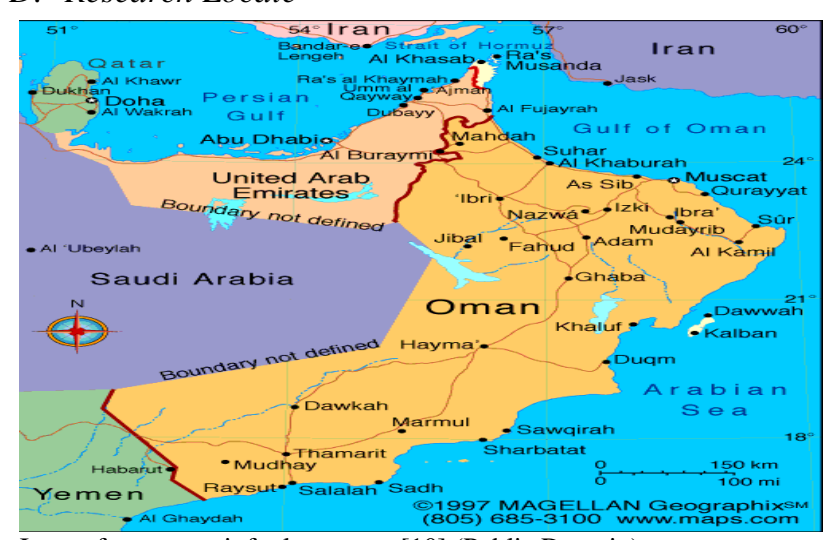

Image from www.infoplease.com [10] (Public Domain)

Fig. 1. Map of Oman.

The setting of the study is conducted in the Sultanate of Oman, located in the south eastern corner of the Arabian Peninsula. Oman is an Islamic open country, which is also a member of Gulf Cooperation Council. The total area of the land is approximately 309.5 thousands square kilometers (see Fig. 1). It is composed of varying topographic areas. The mountain ranges occupy almost $15 \%$ of the total land of Oman. The remaining area is mainly wadis and desert (about $82 \%$ of the total area). The climate differs from one area to another; it is hot and humid in the coastal areas in summer, hot and dry in the interior with exception of higher mountains and Dhofar Governorate, which enjoys a moderate climate throughout the year. The Sultanate of Oman is administratively divided into 5 Regions and 4 governorates with 61 Wilayats. These regions are: $\mathrm{Ad}$ Dakhliyah, Ash Sharqiyah, Al Batinah, Adh Dhahirah, and Al Wusta, and the governorates are: Muscat, Dhofar, Musandam and Al Buraymi Governorates [11].

\section{E. Participants of the Study}

In order to contribute to the international research settings in field of nursing education, nurse educators with at least minimum of 6 months or more are chosen as the coresearchers of this study, born Filipinos by nationality, and originated from the country Philippines, but presently living and working in Oman. The participant selection is described in great detail as supporting the qualitative philosophical basis of the study being those who had experience the phenomenon under investigation. The authors have chosen to protect the true identity of the co-researchers whom have entrusted their sensitive narration, Pseudonym is used to code and represent indirectly the personality and character of the co-researchers to protect the identity and confidentiality of data entrusted in this study. The pseudonyms used are based from the trademark innate characteristics genuine to majority of Filipinos, incomparable, and distinct to every co-researchers,

1) Mapagtaguyod: "She who builds the living standard by being the main source of bread for the family."

2) Maprinsipyo: "She who directs decision in many dealings of her life and work challenges abroad with highly regarded principles."

3) Madasalin: "She who uses prayer as her weapon to protect from evil deeds of individuals' wanting to forsake and punish her."

4) Madiskarte: "She who is strategic in her way of dealings with life and applies tactics to achieve her ambitions in order to improve better their family status."

5) Masayahin: "She who always cheers up and uses laughter as a form of medicine to all life and work stresses she experience during her stay and work abroad."

6) Makalinga: "She who cares for her significant ones, raises individuals to feel secured and comfort especially in the most difficult times and journey of life abroad."

7) Matiisin: "She who has longer thread of patience in many life adversities and work challenges that she encountered in enduring a culture diversified individuals."

8) Matapang: "She who is courageous in winning the life of working overseas and brave enough to resist struggles of the complex situation of living away from loved ones."

9) Mapagkumbaba: "She who humbles herself with all the oppression and deprivation she experienced from work disadvantages and lifted out pressures from bullies."

\section{Narrative Profile of Co-researchers}

Co-researcher 1: Mapagtaguyod a resilient lady who lost her better half, ill parents, and tragic sudden lost of her third son due to vehicular accident, still remains unyield. With all her adaptation challenges at work, she continuously raises the needs of her married children. Her struggle for finances still continues, and feels threatened from unsecured job as her retirement age approaches.

Co-researcher 2: Maprinsipyo a well-experienced mom in gulf countries, sustains the financial obligations needed for education of her children and medical treatment of her husband, whom she eventually lost while attending her work abroad. She expressed the advantage of strong head and collegial support to a stable employment, despite of many hiccups in dealing with western superiors. Her firm principles define her own traits.

Co-researcher 3: Madasalin a christ-centered woman greatly tested with lots of family burdens from critical illness of parents, to the lost of her child, and to extent of losing her job inflicted by superiors' professional bullying and maltreatment. Her dedication to work and compliance with the contract forced her to set aside her dream to complete higher studies. She lifted all her worries through 
church activities, and in a belief that with God, unexpected miracles do happen to change life misfortune.

Co-researcher 4: Madiskarte a strategic mother in raising her small children alone, as abandoned by her husband in exchange for another family and job opportunity. Her jolly attitude still experienced struggles from rift after being outcasted by fellow educators due also to their regional differences. She went through own life-threatening health conditions which she surpassed all challenges alone. Her philantrophic, interpersonal charismatic personality engaged her into business venture. Woman, but temptation weak as she is, tries harder to be wiser for the sake of maintaining self-respect after learning from wrong decisions. Despite all, she finds strength and belongingness from family, peers outside work and close relationship with God.

Co-researcher 5: Masayahin a bubbly mommy, renewed marriage vows to her hubby whom once tempted to be unfaithful due to their distance. She experienced many struggles significantly on first year of stay in Oman. She experienced traumatic sexual harassment which made her frightened to explore her environment. She continuously persevere in proving her worth at work when assumed and loses her managerial position, but remains positive, and enjoys laughter as her way of coping mechanisms.

Co-researcher 6: Makalinga, a caring granny, came out of her shell to attain the dream of working abroad, turned out bread winner to her life-changing challenges in family. The missed chance of losing loved ones to some extent, sustained by her hard-earned money, still loses savings in pursuit of recovering lives of significant ones. Her untiring desire to gain savings to maintain needs of debilitating husband and ill grandchildren, to family she's a diamond.

Co-researcher 7: Matiisin a loving mom of larger group of children and a happily married wife to a house husband. She emotionally endures her physical absence for the sake of children's educational sustenance for fulfillment of ambition to a better family life. She uses "distance mothering" strategy in raising a special kid and children whom went through series of illnesses, surgical operations, and life-taking accident while working in Oman. She's still missing family events and special occasions, diverts her home sickness into recreational or religious group activities.

Co-researcher 8: Matapang a mother of innocents, who fought at her best to keep family ties despite of hiccups in her married life to a husband allegedly had an affair due to their physical distance. She had physical and emotional challenges, work sensitivities with her head, colleagues and students, but remains terribly unbeatable. Optimism and positivity in life spared her from being unemployed.

Co-researcher 9: Mapagkumbaba is graciously single in her middle adulthood. She humbly resembled and reflected on the life of her ex-abroad dad as she realized the difficulty she went through in going through the same challenges. She offers financial aids for married siblings and medical support expenses of aging parents into a more comfortable life in exchange of her physical absence. She solely diverts into religious activities with friends. Like many, she went through unbearable issues with students, and is labeled weak and got bullied.

\section{F. Research Instrument}

Based from first procedural steps of van Manen's methodological interpretation [7], [8], the authors used their personal experience as a starting point of research by turning into the nature of lived experience by orienting to phenomenon. As cited, "the researcher's self is the major instrument for collecting data as it is through the developing relationships that occur in an in-depth interviewing process that the meaning of a lived experience is obtained"[9]. In phenomenology, "The researcher is the primary data collection instrument. It is important, then, for the researcher to conduct a reflective self-assessment prior to initiation of data collection so that bracketing of bias about the experience can occur [12]. In general, phenomenology requires a skilled researcher who is capable of identifying and setting aside his or her bias about an experience. The analysis of the essence of an experience requires reflection and careful viewing techniques. The outcome can provide a valuable addition to evidence about the way individuals respond to events and the meaning of their lived experiences [12].

\section{G. Data Gathering Procedure}

The main focus of the research is phenomenological study on the adaptation challenges of Filipino expatriate nurse educators in a multicultural milieu in the Sultanate of Oman. From the point of researchers' personal experience, the authors developed and formulated the guide questions that are restrospective in nature. These questions are formulated which delved into the co-researcher's life and work experiences abroad. The interview questions are validated by three registered clinical psychologists, and the authors underwent brief training and crisis debriefing on proper delivery of questions and handling of co-researchers' interview process, to anticipate for any uprising emotional breakdown and necessary measures to secure comfort, confidentiality and reassurance of entrusted information.

The authors secured ethical approval from Institutional Ethics Review Committee of St. Paul University Manila, and informed consent permission from the co-researchers, for collection of pertinent information related to the study of human research dissertation. The consent form contained information regarding the study, the process to be followed, and confidentiality to be maintained. The signed consent form is secured for the co-researcher's protection. The interview process in phenomenology requires a high level of skills in eliciting clear and accurate responses from informants. Respondents must be able to reflect their experience and report their responses, so recall and willingness to share sometimes painful events may be stressful for participants [12].

Each interview lasted for a range of 30 minutes to an hour on different days, done in the evenings after work and on weekends, set and mutually agreed upon within a month. The interview is conducted by the authors on varied settings, location and time spent ranging from 4-6 hours per individual with travel time and post interview discussion. The interviews allowed the co-researchers to recall and narrate their experiences before and during the stay abroad. The interview conversations are recorded using an audiovisual recorder, through cellular phones and digital camera which authenticated the trustworthiness and credibility of the study. In exploring the phenomenon, 
gathering data "All recollections of experiences, reflections on experiences, descriptions of experiences, taped interviews about experiences, or transcribed conversations about experiences are already transformations of those experiences". "We gather other people's experiences because they allow us to become more experienced ourselves" [8]. This prologue is later transcribed into document form, written per verbatim in order to have a textual representation of the interview that occurred through the help of nurse support group. All interviews transcribed into document form are consequently translated into English by the authors and proof-read by a master English teacher. The responses that are made in Tagalog or mother-tongue language are reviewed by the Filipino language teacher, and responses are validated by the co-researchers according to their expressed meaning based on the verbatim transcription made. The authors used dynamic equivalence for the translation of the interview to have a more natural rendering of English, while maintaining the meaning as close to the meaning in the original text. The words chosen by the writer needs to take the reader into a "wondrous landscape" as reader is drawn into the textual meaning [6].

In phenomenologic methods, neither the length of time for collecting data nor number of participants is defined before the study starts. Rather, data are collected until all information is redundant of previously collected data - until saturation occurs [13]. The data is saturated at the $6^{\text {th }}$ coresearcher as validated by conducting three (3) more interviews in a hope that there might be additional themes that may emerge. Data saturation is defined and the stopping criterion as being when three (3) consecutive interviews failed to contribute new themes or ideas [14], [15].

\section{FINDINGS AND DISCUSSION}

This section present the findings of adaptation challenges of Filipino expatriate nurse educators obtained from the gist of expressed meaning and theme commonalities in the adaptation challenges experienced by co-researchers, Filipino nurse Educators in Oman.

In compliance to van Manen's method, saturated data is subjected to analysis which called for gleaning thematic descriptions from artistic sources. The authors used arts, music, and painting which dwell into deeper meaning of the thematic descriptions. The authors also engaged then into phenomenological writing, which attended to the speaking of language, interpreted idiomatic expressions and defined etymologic sources into a contemporary meaning that the co-researchers have conveyed varying the examples, indepth writing, and thorough rewriting by the authors in a deeper exploration and broader interpretations and understanding of the experiences shared by the coresearchers. The phenomenological method cannot be separated from the practice of writing. Writing up the results of qualitative analysis is an active struggle to understand and recognize the lived meanings of the phenomena studied. The text written by a phenomenological researcher must lead readers to a questioning wonder [6]"

The authors discovered etymologic sources lifted like
Bread and Butter, Pinoy, camsa rial, wasta system, crabs, bamboo, and other sources that nurture the meaning of phenomenon, and some relevant idiomatic phrases are noticed and interpreted such as "No Man is an Island", "Cry a River", and "Bite the Bullet" which emerged on its respective themes noticed and interpreted. As the coresearchers described their experiences and phenomenological literatures have supported it, the use of music especially in the lyrics of "There can be Miracles when you Believe", "A Friend", and "Wind Beneath my Wings", which further enriched the interpretation of the meaning of the phenomenon of co-researchers' adaptation challenges. The presence of paintings such as Wrecking Blows, Footprints on the sand, and Philippine Eagle Flagship gave authors' ownership on phenomenon.

In composing linguistic transformation, the authors made use of philosophical inquiry, which eventually developed creative expressions for articulating themes. Theme provides focus, meaning, and a point to lived experience. "Themes are the stars that make up the universes of meaning we live through. By the light of these themes we can navigate and explores such universes" [8]. Each focus upon the emergent aspects: for example, physical, social emotional, psychological, and spiritual challenges, depending on the result of transcribed data information from the interview.

In attending to the phenomenological writing through gleaning thematic descriptions from artistic sources, the researcher studied sources of art that may reflect thematic elements of this study. Art renders a unique perspective because "the artist recreates experiences by transcending them" [8]. The meaning of the phenomenon is enriched along with art such as Falcon inside a Cage, Orient Pearls, Classic Diamonds, and Glass Hour.

In order to understand a lived experience and make it somehow tangible, the authors made use and described a variety of relevant and relative examples, like Culture of Crabs, Bite the Bullet, Filipinos are like Bamboos, became immersed in the phenomenon, which made aspects of the phenomenon accessible to the real world.

The art of phenomenology allows to craft scientifically rigorous research in a style that reflects the authors' orientation to the world. The authors fitted Filipino Nurses Educators according to their common description as Resilient Bamboos, made use of Philippine Eagle Flagship which also symbolized overseas Filipino workers who represents their distinctive characteristics known to world, and its prestige of people and country. In the process of writing and rewriting, it is more reminiscent of the artistic activity of creating an art object that has to be approached again and again...going back and forth between the parts and the whole in order to arrive at a finely crafted piece that often reflects the "personal signature of the author"[8].

As the researcher translated the co-researchers experiences into shared themes, the researcher has a clearer understanding of the phenomenon. Essential themes are those that speak to the shared experience of the phenomenon and without them the phenomenon would be altered [8] (see Table II). 
TABLE II: CATEGories, SUB-THEMES, AND THEMES OF PERILS, PITFALLS, PRISTINE PEARLS, AND PRESTIGE OF PINOY EXPATRIATES

\begin{tabular}{|c|c|c|}
\hline Categories & Sub-theme & $\begin{array}{l}\text { Major } \\
\text { Theme }\end{array}$ \\
\hline $\begin{array}{l}\text { Conditioning Family Members } \\
\text { in fulfilling Dreams and } \\
\text { Ambitions }\end{array}$ & $\begin{array}{l}\text { Flying Falcon in its } \\
\text { Bewilderness }\end{array}$ & PERILS \\
\hline $\begin{array}{l}\text { Landing Falcon trapped in a } \\
\text { Cage } \\
\text { Two-facets coin in the Claws } \\
\text { of flying Falcon } \\
\text { Falcon Battling with Others } \\
\text { and the existing world } \\
\text { (Culture Shock) } \\
\text { Falcon Lost and Miss } \\
\text { Directions }\end{array}$ & $\begin{array}{l}\text { Self-Sacrificing } \\
\text { Falcon in } \\
\text { Ambivalence }\end{array}$ & \\
\hline $\begin{array}{l}\text { Filipino Ethnical and Regional } \\
\text { Differences } \\
\text { Culture of Crabs }\end{array}$ & \begin{tabular}{|l|} 
Cultural \\
Differences and \\
Diversities \\
\end{tabular} & \\
\hline \multicolumn{2}{|c|}{ Personal Agonies of Pinoy Expatriates } & PITFALLS \\
\hline $\begin{array}{l}\text { Physical Challenges } \\
\text { Emotional Challenges } \\
\text { Psychological Challenges } \\
\text { Spiritual Challenges } \\
\text { Safety, Security, and Comfort } \\
\text { Misery }\end{array}$ & $\begin{array}{l}\text { 1. Personal } \\
\text { Challenges }\end{array}$ & \\
\hline $\begin{array}{l}\text { Flight Moments } \\
\text { Glass Hour } \\
\text { Threatened and Unsecured Job }\end{array}$ & 2. Wrecking Blows & \\
\hline $\begin{array}{l}\text { Savings versus Losses } \\
\text { Salary Delayed is Salary } \\
\text { Denied } \\
\text { Control Savings, Give Limits, } \\
\text { but self-deprived } \\
\end{array}$ & $\begin{array}{l}\text { 3.Financial } \\
\text { Constraints }\end{array}$ & \\
\hline \multicolumn{2}{|c|}{ Professional Hurdles of Pinoy Nurse Educators } & PITFALLS \\
\hline $\begin{array}{l}\text { Head-Colleague Collision } \\
\text { Teacher versus Students' } \\
\text { Standard and Discipline } \\
\text { Technology Outdated } \\
\end{array}$ & $\begin{array}{l}\text { 1.Academic } \\
\text { Challenges }\end{array}$ & \\
\hline $\begin{array}{l}\text { Different Country, Different } \\
\text { System Practice, Different } \\
\text { Approach }\end{array}$ & $\begin{array}{l}\text { 2. Clinical } \\
\text { Challenges }\end{array}$ & \\
\hline $\begin{array}{l}\text { Family's Bread and Butter } \\
\text { Money Exchanges Saves } \\
\text { Family Life and Future } \\
\text { Overseas Family Worker's } \\
\text { Investments and Rewards } \\
\text { Doors of Opportunities for } \\
\text { Professional Growth } \\
\end{array}$ & $\begin{array}{l}\text { 1. Aim-based } \\
\text { Adaptation }\end{array}$ & $\begin{array}{l}\text { PRISTINE } \\
\text { PEARLS }\end{array}$ \\
\hline $\begin{array}{l}\text { Smart Assertiveness } \\
\text { Collaborative Professional } \\
\text { Relationship } \\
\text { Respect \& Understanding of } \\
\text { Culture } \\
\text { Cry A River } \\
\text { Bite the Bullet } \\
\end{array}$ & $\begin{array}{l}\text { 2. Behavior and } \\
\text { Values -based } \\
\text { Adaptation }\end{array}$ & \\
\hline $\begin{array}{l}\text { Bridge Emotional Gaps via } \\
\text { Constant Appearance and } \\
\text { Communication } \\
\text { Drawing Strengths from } \\
\text { Loved Ones } \\
\text { Strengthening Partnership } \\
\text { Distance Mothering } \\
\end{array}$ & $\begin{array}{l}\text { 3. Communication- } \\
\text { based Adaptation }\end{array}$ & \\
\hline $\begin{array}{l}\text { Direct Relationship with God } \\
\text { There can be Miracles } \\
\text { Prayer Activity Support Group } \\
\text { Forgiveness and } \\
\text { Reconciliation }\end{array}$ & $\begin{array}{l}\text { 4. Divine God- } \\
\text { based Adaptation }\end{array}$ & \\
\hline $\begin{array}{l}\text { No Man is an Island } \\
\text { Managers Advocacy \& } \\
\text { Rewarding support } \\
\text { Work like One Family } \\
\text { Balancing Work and Life } \\
\text { through diversified optimistic } \\
\text { activities }\end{array}$ & $\begin{array}{l}\text { 5. External Others } \\
\& \text { Activity based } \\
\text { Adaptation }\end{array}$ & \\
\hline
\end{tabular}

\begin{tabular}{||l||l||l||}
\hline \hline Adaptation rooted \& grow & 1.Resilient & PRESTIGE \\
through nurturance of Family & Bamboos & \\
\& Parents background and & \\
Moral Values & \\
Eternal patience and Tensile & \\
inner strength & \\
Feet on the Ground & \\
\hline \hline Building Blocks: & \\
Remembering Training Origin & 2.Forging Orient & \\
for Years of Learning & Diamonds & \\
Experience & \\
Developing Control of & \\
Emotional Intelligence (EQ) & \\
Value Gratitude \& Service & \\
Dedication & \\
\hline \hline Alertness \& Positive Mind & 3.Philippine Eagle & \\
Conditioning, Upmoving the & Flagship \\
Will \& Self-determination & \\
Commitment and Dedication & \\
to Work & \\
Establishing Credibility & \\
Integrity, and Legacy & \\
(Professionalism in Teaching & \\
and Selfless Mentoring) & \\
Pride and Accountability of & \\
Filipino's Reputation & \\
\hline \hline
\end{tabular}

After a tedious analysis of the commonalities of all findings, the categories are reduced from 114 categories into 53 categories. Initially, 20 subthemes emerged but reduced into the final 16 subthemes. Lastly, four major themes emerged and presented in a form of matrix table. 5

\section{CONCLUSION AND RECOMMENDATION}

\section{A. Conclusion}

The findings of the study from the phenomenological query raised the conclusion, that Filipino Nurse Educators in Oman faced a lot of adaptation challenges during their work experiences in carrying out their roles and responsibilities to their organization, along with their huge obligations with their families back in Philippines. This arose four major themes such as Perils, Pitfalls, Pearls and Prestige of Pinoy Nurse Educators. The following conclusions are derived from the major themes:

Perils and pitfalls of Pinoy expatriates:

1) There is a need to condition the family members about the departure of the Filipino Overseas Worker.

2) There is a lack of awareness and orientation to the host country and the workplace they immersed with.

3) The lack of education on the kind of cultural practices in their living and workplace along with the existing multicultural races in the host country complicated their challenges.

4) Their battle with homesickness and loneliness are being worsened by their agonies with their personal life and professional hurdles during their adjustment and adaptation period in the host country.

5) While the Pinoy Expatriate is making their selfsacrifices for the family members, they are not prepared to deal with unfortunate events that happened with their loved ones.

Although there are difficulties and adversities, the authors found out that their sacrifices are also having a good outcome and these are described as:

Pearls and prestige of Pinoy expatriates: 
1) The monetary exchanges from income saves life of family members and meet their financial needs along with their tangible investments for future living

2) There are opportunities for professional and career growth with assertiveness and self-determination.

3) The Pinoy Expatriates become closer to God and strengthen the faith at all times and not only during difficult times.

4) It makes them a better person and teaches a lot of life learning experiences with all their struggles that they have been through.

5) The Pinoy Expatriates learn to value the importance of their work and prove that by excelling in their career, they are responsible in bringing pride and honor to their fellow countrymen.

There is indeed a strong mandate need for reinforcement of policies and revisit the rules of immigration particularly to skilled and professional Overseas Filipino Workers.

\section{B. Recommendations}

Recommendations for departing Overseas Filipino Workers $(O F W)$ - Filipinos who plan to depart to another country for employment should be advised to think deeply on the repercussions of their decision. This is to anticipate the challenges of living and working abroad, which is mentioned in this study as Perils and Pitfalls in order to rationally prepare self, in a holistic manner.

Recommendations for POEA and the recruitment Agencies - The POEA can review the existing policy and program in PDOS to include self-reflection of OFW before going abroad, facilitated by recruitment agencies and POEA. The knowledge and experience sharing may bring into their awareness, the adaptation challenges faced by our Overseas Filipino Workers as a reflective guide to a more controlled and efficient implementation of transparent policies in the government in terms of recruitment and deployment.

Recommendations for nursing education - The integration of the possible life changing experiences that nurses may face when working in a different country may be included when planning changes in the curriculum. This modest miniscule may serve as the beginning of looking to reality among expatriate nurses with hope of encouraging curriculum planners to see this aspect in the lives of nurses. The findings also supports the necessity for inclusion of Geographical-Transcultural Nursing as a valuable addition to the concepts in Nursing Curriculum, a subject that will educate future Filipino nurses on the background of the culture, customs, and practices for broader understanding and awareness and behavior-appropriate measures in the host country.

Recommendations for nursing service - The revealing challenges experienced by Filipino nurse educators working as clinical instructors in different clinical hospitals in Oman brought valuable contribution to the need for a reflective clinical practice of Filipino nurses. This study brought sensitization and awareness emphasizing special attention in handling nursing students of other countries in terms of study motivation and discipline during clinical exposure. The possible revisit of Induction program and inclusion of planned clinical instruction for clinical hospital affiliation system may be included when reviewing the rules and regulations on the proper decorum and students' roles and responsibilities in the course of clinical training

Recommendations for further research - Although the findings of this research focused on nurse educators, the holistic aspect of the life and work experiences of the Filipinos working abroad in general, stroke the main essence and interest of the study which is expatriates' life and their struggles or challenges faced in working abroad. This study opens gateway for replication of similar study interests to opposite gender in both Nursing and Non-nursing profession, and eventually to other nationalities of expatriates as a benchmarking research strategies.

\section{ACKNOWLEDGMENT}

Words are not enough to thank Dr. Lily Famadico, Dr. Florencia Maldia, Dr. Elizabeth Ramos, and Dr. Nieves Medina of St. Paul University Manila; Dr. Pricila Marzan, Dr. Geraldine Tria, and Dr. Consuelo Malaluan, registered psychologists; Lourna Tagay, Melandro Santos and Donna Cabiao, proof-readers and translators; Maritess Abordo, Ruel Yaba, Yves Esteban, and Janeylee Abogado, data transcriptionist; Maria Bianca Carlos, research assistant; Salim Bader Al Bader, audio-video record support; lastly heartfelt gratitude to the nine female co-researchers for their valuable responses.

\section{REFERENCES}

[1] R. Elleray, "Kierkegaard, socrates and existential individuality," Richmond Journal of Philosophy, p. 16, 2007.

[2] T. Siljanen, "Narratives of expatriates in the Middle East," Adaptation, Identity and Learning in Non-Profit Organization, University Printing House of Jyvaskyla, 2007.

[3] The free Dictionary. [Online]. Available: http://www.thefreedictionary.com

[4] C. Boswell and S. Cannon, Nursing Research: Incorporating Evidenced based Practice, Jones \& Bartlett Publishers LLC, 2007.

[5] N. Burns and S. Groves, Understanding Nursing Research. Building an Evidence-based Practice, $4^{\text {th }}$ ed. Singapore: Elsevier, 2007.

[6] D. Polit and C. Beck, Nursing Research: Generating and Assessing Evidence for Nursing Practice, $8^{\text {th }}$ ed. Philadelphia: Lippincott Williams \& Wilkins, 2008

[7] H. Speziale and D. Carpenter, Qualitative Research in Nursing, $4^{\text {th }}$ ed. Philadelphia: Lippincott Williams and Wilkins, 2007.

[8] M. Van Manen, Researching Lived Experience: Human Science for an Action Sensitive Pedagogy, USA: The State University of New York Press, 2010.

[9] R. Watson, H. McKenna, S. Cowman, and J. Keady, Nursing Research, Philadelphia: Elsevier Publishing Inc, 2008.

[10] Inforplease. [Online]. Available: http://www.infoplease.com

[11] Ministry of Health (MOH), Directorate General of Planning, Annual Health Report, 2011, vol. 1, pp. 1-4.

[12] J. Houser, Nursing Research Reading, Using and Creating Evidence, Massachusetts: Jones and Bartlett Publishers LLC, 2008.

[13] C. MacNee and S. McCabe, Understanding Nursing Research, Reading and Using Research in Evidenced based Practice, $2^{\text {nd }}$ ed. Philadelphia, USA: Lippincott, Williams and Wilkins, 2008.

[14] G. Hofstede, G. J. Hofstede, and M. Minkov, Cultures and Organizations, Software for the Mind, third Edition, 3rd ed. London, England: Mc Graw Hill, 2010.

[15] P. Gill, J. Hislop, D. Mant, and A. Harnden, "General practitioners' views on quality markers for children in UK primary care: A qualitative study," BMC Family Practice, vol. 13, no. 92, 2012.

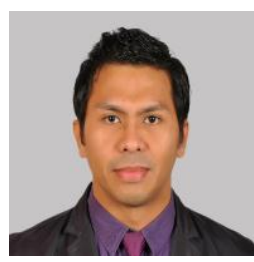

Francis C. Lazarte is a physical therapist, nurse, and midwife. He earned PhD in nursing education with major in leadership and management, in March 2014, from St. Paul University Manila, Philippines. His gift in publishing research is potentiated by struggles and soaring success from all challenges in Oman for over 4 years as "roller coaster phenomenon". 
Dr. Lazarte especially dedicated this study to loving parents, Edgardo M. Lazarte, and Pricila Carlos-Lazarte; and in memory of Jerom "Vincent" Hidalgo Ortega, whom has joined Creator last May 04, 2015, and will forever be remembered as the "wind beneath the wings".

Dr. Lazarte also presented his researches in many international conferences of multi-professionals in countries like Geneve, Switzerland last October 10-11, 2014; Dubai, United Arab Emirates last May 5-6, 2015 , and recently in International Council of Nurses (ICN) conference held last June 18-23, 2015 in Seoul, South Korea. Dr. Lazarte is now the president, CEO and owner of Amitie Review, Research and Training Center Inc. (ARRTCI), a SEC-registered company pioneered in Davao City, Philippines, established to provide professional review, research assistance, continuing skills training, and education for healthcare and non-healthcare professionals, and exponentially expanding its international networks. He is also a real estate investor, and huge land coconut-farm owner in CamSur.

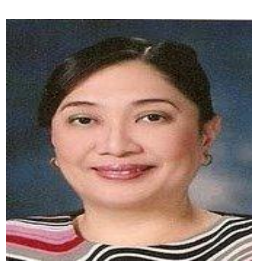

Maria Irma Bustamante was born on January 28 , 1958. She finished both her BSN and MAN with highest honors at University of Santo Tomas; and $\mathrm{PhD}$ in nursing at University of Philippines. She became a faculty member of UST in both Bachelor and Graduate School. She also worked in university with executive position in countries, Pakistan and Brunei. She did series of publication, mostly can be accessed Online, focus on women empowerment, mostly presented in international conferences in countries like Amsterdam, Bahrain, Hongkong, Lebanon, Malaysia, South Africa, Thailand, and USA are among others. At present, Dr. Bustamante is the dean of College of Nursing and Graduate school of St. Paul University Manila.

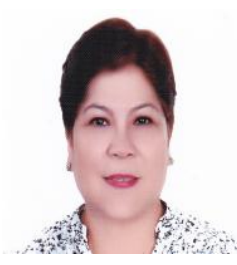

Ada Estephania Borial Bonina was born on November 1, 1958. She is a loyal alumnus of Aquinas University in Bicol region, with recognition from her bachelor, masters, and doctorate degree. She is a mother of 4 grown-up children named Ronald, Rogene, Heloise and Romark. Her success in career is nurtured by her mother, Dr. Gregoria Benosa, supported by deceased husband Rubencito.

Currently, Dr. Bonina is working in her specialty as a tutor in NeonatalPediatric Nursing Program, OSNI. She is also a faculty member of BSc (Hons) Nursing Practice Programme of Cardiff University, Wales, UK.

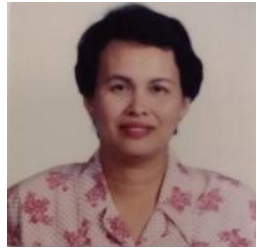

Nida Yu Baldo was born on September 9, 1955 in Barcelona Sorsogon. She finished bachelor in nursing, master, and doctorate degree in Aquinas University, Legazpi. She dedicates her success to beloved husband, Nestor (deceased), and son Rey Joseph (deceased). She draws inspiration from her children Carmela Blanca, Jessica Joyce, and John Benedict. Dr. Baldo is currently working as a faculty member of RNI since 2004, teaching basic diploma Nursing Program, and BSN program.

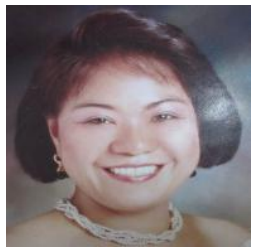

Imelda De Leon Canlas was born on April 14, 1959. She recently finished her doctorate degree in PCHSI. She strives harder being single mom to her 2 lovely children Jacqueline and Michael Zialcita, and enjoys her grandsons, Eshawn and Hunter. Dr. Canlas dedicated her 13 years of teaching in ONI under basic diploma and bachelor degree program specialize in nursing pharmacology, med-surgical nursing, leadership and management. Dr. Canlas is active into social philanthropic activities. 